$\begin{array}{ll}\text { Research Square } & \text { Preprints are preliminary reports that have not undergone peer review. } \\ \text { They should not be considered conclusive, used to inform clinical practice, } \\ \text { or referenced by the media as validated information. }\end{array}$

\title{
Female Genital Mutilation/Cutting (FGM/C) coding capacities in Swiss University Hospitals using the International Classification of Diseases (ICD)
}

\author{
Sara Cottler-Casanova \\ Swiss Tropical and Public Health Institute \\ Mathide Horowicz \\ Geneva University Hospitals \\ Angèle Gayet-Ageron \\ Geneva University Hospitals \\ Jasmine Abdulcadir ( $\sim$ Jasmine.Abdulcadir@hcuge.ch ) \\ Geneva University Hospitals
}

\section{Research Article}

Keywords: Female Genital Mutilation, Female Genital Cutting, Female Genital Mutilation/Cutting, indirect estimates, prevalence, coding, International Classification of Diseases, ICD, Switzerland.

Posted Date: December 18th, 2020

DOI: https://doi.org/10.21203/rs.3.rs-120372/v1

License: @ (i) This work is licensed under a Creative Commons Attribution 4.0 International License. Read Full License 


\section{Abstract}

Background: To assess the number of inpatient women and girls in Swiss university hospitals from countries with high female genital mutilation/cutting (FGM/C) prevalence, and of inpatients with a coded diagnosis of FGM/C.

Methods: Exploratory descriptive study in Switzerland to assess the number of women and girls

admitted to Swiss university hospitals between 2016 and 2018 from $30 \mathrm{FGM} / \mathrm{C}$ high prevalence countries (1), inpatients with a coded diagnosis of FGM/C (2). Participating hospitals provided anonymized data for all inpatient women and girls from $30 \mathrm{FGM} / \mathrm{C}$ practicing countries, and for all inpatients with a coded diagnosis of FGM/C. We calculated indirect estimates of inpatient women and girls with FGM/C and compared them with the number of inpatients with a coded diagnosis of FGM/C.

Results: 8720 women and girls from countries with high prevalence of FGM/C were admitted. 207 patients were coded with FGM/C, including 7 with a nationality outside the 30 targeted countries, corresponding to an overall prevalence of $2.3 \%(95 \% \mathrm{Cl}: 2.0-2.6)$. The number of $\mathrm{FGM} / \mathrm{C}$ cases by hospital was significantly different across year $(P<0.001)$, with a higher proportion of cases collected in Geneva.

Conclusions: The comparison between indirect estimates of inpatients with or at risk of FGM/C and the low number of FGM/C cases coded, suggests low recording and coding capacities of FGM/C.

Funding: Swiss Federal Office of Public Health and Swiss Network against Female circumcision, Caritas Switzerland.

\section{Introduction}

Female genital mutilation/cutting (FGM/C) is the partial or total removal of the external female genitalia for non-medical reasons ${ }^{1}$. The World Health Organization describes four FGM/C types (Table 1). 200 million women and girls have undergone the practice according to the Demographic Health Survey (DHS) developed by ICF International or the Multiple Indicator Cluster Surveys (MICS) directed by UNICEF, conducted in 27 African and three Asian countries practicing FGM/ ${ }^{3}$. These estimates do not include women and girls living with $\mathrm{FGM} / \mathrm{C}$ who emigrated from FGM/C practicing countries ${ }^{3}$. In the European Union (EU), there were an estimated 500,000 women and girls living with $\mathrm{FGM} / \mathrm{C}$ in $2011^{4}$, and 14,700 in Switzerland in $2013^{5}$ based on indirect measures, where the number of migrant women from a FGM/C practicing country is multiplied by the FGM/C prevalence rate from the same country. The European Institute for Gender Equality estimated the number of girls aged 15 to 19 at risk of FGM/C between 2011 and 2016, as 44,106 in France; 18,339 in Italy; 6,122 in Belgium, and a few hundred in Greece, Cyprus, Malta, Ireland, Portugal and Sweden ${ }^{6,7}$. 
Table 1

Classification of FGM/C according to $\mathrm{WHO}^{2}$. When WHO refers to "clitoris", it is in reality the external part of the clitoris: the glans, more or less part of the body of the clitoris.

\begin{tabular}{|c|c|}
\hline $\begin{array}{l}\text { Type I } \\
\text { Type la }\end{array}$ & $\begin{array}{l}\text { Partial or total removal of the clitoral glans (the external and visible part of the clitoris, which is a sensitive part of the } \\
\text { female genitals, with the function of providing sexual pleasure to the woman), and/or the prepuce/clitoral hood (the } \\
\text { fold of skin surrounding the clitoral glans). }\end{array}$ \\
\hline \multirow[t]{2}{*}{ Type lb } & Removal of the prepuce/clitoral hood only \\
\hline & Removal of the clitoral glans with the prepuce/clitoral hood \\
\hline Type II & Partial or total removal of the clitoral glans and the labia minora, with or without removal of the labia majora. \\
\hline Type Ila & Removal of the labia minora only \\
\hline Type Ilb & Partial or total removal of the clitoris and the labia minora \\
\hline Type Ilc & Partial or total removal of the clitoris, the labia minora and the labia majora \\
\hline $\begin{array}{l}\text { Type III } \\
\text { (Infibulation) }\end{array}$ & $\begin{array}{l}\text { Narrowing of the vaginal opening with the creation of a covering seal. The seal is formed by cutting and } \\
\text { repositioning the labia minora, or labia majora. The covering of the vaginal opening is done with or without removal } \\
\text { of the clitoral prepuce/clitoral hood and glans. }\end{array}$ \\
\hline Type IIla & Removal and apposition of the labia minora \\
\hline гуре пाт & Removal and apposition of the labia majora \\
\hline Type IV & $\begin{array}{l}\text { All other harmful procedures to the female genitalia for non-medical purposes, for example, pricking, piercing, } \\
\text { incising, scraping and cauterization. }\end{array}$ \\
\hline
\end{tabular}

Indirect estimation is a systematic and affordable method for estimating the number of women with FGM/C in high-income countries ${ }^{8-}$

10 . However, due to several reasons, including cultural change and varying socioeconomic, and ethnic origins of migrants, it may not reflect the actual FGM/C prevalence in migrants' country of residence or community ${ }^{11,12}$. The real prevalence and incidence of FGM/C and the number of minors at risk remains unknown in many countries.

Direct measures may provide more accurate estimates that could guide policy- and clinical decision-making. Surveying samples of migrants to estimate FGM/C prevalence also has limitations, as they might not know whether they experienced FGM/C or be unaware of the type ${ }^{13}$. Swiss hospital data may provide a sample of patients that can be used to describe the prevalence of FGM/C in Swiss hospitals. Furthermore, hospital data represents an opportunity to study access and quality of care for patients who underwent FGM/C, providing guidance for health interventions ${ }^{14-16}$.

No data are available on the number of women and girls with FGM/C in Swiss hospitals. No accurate information is available on Swiss healthcare professionals' capacities to record FGM/C and deal with its complications and prevention. Weak capacities in diagnosis, recording and coding represent the major obstacle to studying hospital data on FGM/C. Studies from Switzerland and other high- and low-income countries, among midwives, gynecologists and obstetricians, general and travel medicine practitioners have shown difficulties in screening, diagnosing, classifying and recording FGM/C ${ }^{17-22}$. Pediatricians also lack training on FGM/C and rarely perform external genital examinations ${ }^{23,24}$.

In this manuscript, we aim to:

(1) Assess the number of women and girls from FGM/C practicing countries admitted to Swiss university hospitals,

(2) Estimate, using indirect measures, the potential number of inpatients who are possibly living with FGM/C.

(3) Measure the number of inpatients with a coded primary or secondary diagnosis of FGM/C. The comparison between indirect estimates of inpatients with FGM/C and the number of FGM/C cases coded in the same hospitals, can inform the diagnostic, recording and coding capacities of FGM/C in Swiss university hospitals.

\section{Methods}


This cross-sectional study was part of a larger research study approved by the Swiss ethics committee. We first calculated the indirect prevalence of women and girls living with FGM/C in Switzerland between 2010 and 2018, by taking the most recent FGM/C DHS and MICS prevalence figures in FGM/C practicing countries and applying them to the number of migrant women and girls from these countries. Full details are available in another paper [Table S1].

Secondly, in February 2019, we asked the five Swiss university hospitals to provide anonymized data for all inpatient women and girls from the $30 \mathrm{FGM} / \mathrm{C}$ practicing countries, and for all inpatients with a diagnosis of FGM/C between 2016 and 2018. In Swiss hospitals, healthcare professionals record diagnosis in patients' electronic medical charts, and professional coders code this information with the tenth edition of the International Classification of Diseases (ICD) ${ }^{25}$. We received data from the University Hospitals of Geneva (HUG), Lausanne (CHUV), Bern and Zurich. The University Hospital of Basel did not participate due to logistical difficulties in data provision. Once received the data, we compiled each hospital's statistical output. Analysis was carried out using STATA version 15.

The participating hospitals provided data on all inpatient women and girls from the 30 targeted countries and all primary and secondary diagnoses of FGM/C coded between January 1, 2016 and December 31, 2018. Duplicates were deleted. Therefore, we estimate indirect prevalence of $\mathrm{FGM} / \mathrm{C}$ as the proportion of the total number of $\mathrm{FGM} / \mathrm{C}$ cases recorded on the total number of women and girls from the targeted countries in four Swiss university hospitals between 2016 and 2018. Inpatients with an FGM/C diagnosis from other countries than the ones targeted were not considered in this estimation.

We provided descriptive statistics with mean, \pm standard deviation (SD), and median for continuous variables; number and proportions by categories for qualitative variables. We compared all categorical variables by year and FGM/C type by region (West Africa vs. East Africa) using Chi-2 or Fischer's exact tests. We compared mean ages by year using non-parametric Kruskal-Wallis test. We estimated indirect FGM/C prevalence in participating hospitals between 2016 and 2018 and their $95 \%$ confidence intervals (95\%Cls) using the binomial exact method.

\section{Results}

8720 women and girls from countries with high FGM/C prevalence were admitted between 2016 and 2018 : 4388 in Bern, 2372 in Geneva, 1218 in Lausanne and 742 in Zurich [Table 2]. Most of them came from Eritrea (31.0\%), followed by Somalia in Geneva, Zurich and Bern (11.6\%), and Cameroon in Lausanne (9.7\%). 
Table 2

Total Number of Women and Girls in Swiss University Hospitals between 2016-2018 from 30 FGM/C High Prevalence Countries

\begin{tabular}{|c|c|c|c|c|c|}
\hline Country of origin & Lausanne Total & $\begin{array}{l}\text { Zürich } \\
\text { Total }\end{array}$ & $\begin{array}{l}\text { Geneva } \\
\text { Total }\end{array}$ & $\begin{array}{l}\text { Bern } \\
\text { Total }\end{array}$ & Total \\
\hline Benin & 12 & 2 & 18 & 5 & 37 \\
\hline Burkina Faso & 12 & 3 & 54 & 21 & 90 \\
\hline Cameroon & 256 & 52 & 261 & 274 & 843 \\
\hline Central African Republic & 1 & 1 & 3 & 3 & 8 \\
\hline Chad & 1 & 2 & 2 & 13 & 18 \\
\hline Djibouti & 4 & 0 & 3 & 0 & 7 \\
\hline Egypt & 15 & 20 & 107 & 101 & 243 \\
\hline Eritrea & 295 & 167 & 362 & 1881 & 2705 \\
\hline Ethiopia & 100 & 59 & 123 & 287 & 579 \\
\hline Gambia & 3 & 7 & 8 & 16 & 34 \\
\hline Ghana & 6 & 42 & 53 & 79 & 180 \\
\hline Guinea & 41 & 8 & 101 & 31 & 181 \\
\hline Guinea-Bissau & 14 & 0 & 9 & 2 & 25 \\
\hline Indonesia & 12 & 20 & 33 & 64 & 129 \\
\hline Iraq & 74 & 66 & 164 & 481 & 785 \\
\hline Ivory Coast & 47 & 41 & 146 & 72 & 306 \\
\hline Kenya & 6 & 41 & 63 & 125 & 235 \\
\hline Liberia & 3 & 2 & 5 & 5 & 15 \\
\hline Mali & 1 & 2 & 32 & 6 & 41 \\
\hline Mauritania & 1 & 0 & 27 & 1 & 29 \\
\hline Niger & 4 & 0 & 23 & 11 & 38 \\
\hline Nigeria & 36 & 42 & 88 & 169 & 335 \\
\hline Senegal & 42 & 5 & 195 & 29 & 271 \\
\hline Sierra Leone & 3 & 4 & 20 & 23 & 50 \\
\hline Somalia & 157 & 101 & 233 & 523 & 1014 \\
\hline Sudan and South Sudan & 2 & 30 & 79 & 63 & 174 \\
\hline Tanzania & 1 & 7 & 33 & 13 & 54 \\
\hline Togo & 61 & 3 & 78 & 36 & 178 \\
\hline Uganda & 1 & 3 & 28 & 24 & 56 \\
\hline Yemen & 7 & 12 & 21 & 20 & 60 \\
\hline Grand Total & 1218 & 742 & 2372 & 4388 & 8720 \\
\hline
\end{tabular}

207 inpatient women and girls had a coded diagnosis of FGM/C [Table 3]. The number of FGM/C cases by center was significantly different by year $(P<0.001)$ with more cases in Geneva overall. The number of cases was significantly different by department $(P<$ $0.001)$ with most cases coded in obstetrics. Patients with an FGM/C diagnosis mostly originated from Eritrea $(n=85)$ and Somalia $(n=$ 
54). At CHUV, seven patients with a coded diagnosis of FGM/C were registered as Swiss $(n=4)$, Ecuadorian $(n=1)$, Turkish $(n=1)$ and French $(n=1)$. 
Table 3

Description of patients with a FGM/C ( $n=207)$ as main or secondary diagnosis between 2016 and 2018 followed in one of four Swiss University Hospitals (Geneva, Lausanne, Bern and Zurich).

\begin{tabular}{|c|c|c|c|c|}
\hline Variables & $\begin{array}{l}2016 \\
(n=42)\end{array}$ & $\begin{array}{l}2017 \\
(n=69)\end{array}$ & $\begin{array}{l}2018 \\
(n=96)\end{array}$ & $P$ value \\
\hline Center, n (\%) & $20(47.6)$ & $24(34.8)$ & $67(69.8)$ & \multirow[t]{5}{*}{$<0.001^{\mathrm{a}}$} \\
\hline Geneva & $13(31.0)$ & $10(14.5)$ & 19 (19.8) & \\
\hline Lausanne & $3(7.1)$ & $23(33.3)$ & $6(6.3)$ & \\
\hline Bern & $6(14.3)$ & $12(17.4)$ & $4(4.2)$ & \\
\hline \multicolumn{4}{|l|}{ Zurich } & \\
\hline Country of origin, $n(\%)$ & $0(0)$ & $0(0)$ & $1(1.0)$ & \multirow[t]{17}{*}{$0.097^{a}$} \\
\hline Benin & $1(2.4)$ & $2(2.9)$ & $0(0)$ & \\
\hline Burkina Faso & $1(2.4)$ & $0(0)$ & $0(0)$ & \\
\hline Cameroon & $0(0)$ & $0(0)$ & $5(5.2)$ & \\
\hline Egypt & $12(28.6)$ & $37(53.6)$ & $36(37.5)$ & \\
\hline Eritrea & $2(4.8)$ & $3(4.4)$ & $2(2.1)$ & \\
\hline Ethiopia & $0(0)$ & $0(0)$ & $6(6.2)$ & \\
\hline Guinea & $0(0)$ & $0(0)$ & $2(2.1)$ & \\
\hline Guinea-Bissau & $1(2.4)$ & $1(1.5)$ & $1(1.0)$ & \\
\hline Ivory Coast & $0(0)$ & $0(0)$ & $1(1.0)$ & \\
\hline Mali & $0(0)$ & $0(0)$ & $1(1.0)$ & \\
\hline Mauritania & $1(2.4)$ & $1(1.5)$ & $3(3.1)$ & \\
\hline Nigeria & $0(0)$ & $0(0)$ & $3(3.1)$ & \\
\hline Senegal & $14(33.3)$ & $18(26.1)$ & $22(22.9)$ & \\
\hline Somalia & $1(2.4)$ & $1(1.5)$ & $3(3.1)$ & \\
\hline Sudan and South Sudan & $9(21.4)$ & $6(8.7)$ & $10(10.4)$ & \\
\hline \multicolumn{4}{|l|}{ Unknown or other } & \\
\hline Service, n (\%) & $13(31.0)$ & $12(17.4)$ & $9(9.4)$ & \multirow[t]{5}{*}{$<0.001^{\mathrm{a}}$} \\
\hline Gynecology & $1(2.4)$ & $23(33.3)$ & $6(6.3)$ & \\
\hline Gynecology or Obstetrics & $23(54.8)$ & $33(47.8)$ & $79(82.3)$ & \\
\hline Obstetrics & $5(11.9)$ & $1(1.5)$ & $2(2.1)$ & \\
\hline Others & & & & \\
\hline Mean age at first visit ( \pm SD, median) & $30.7( \pm 12.0,27)$ & $27.7( \pm 6.1,27.4)$ & $29.8( \pm 6.7,30)$ & $0.162^{b}$ \\
\hline
\end{tabular}

${ }^{\mathrm{a}}$ Fischer's exact test; ${ }^{\mathrm{b}}$ Kruskal-Wallis nonparametric test

Page $7 / 14$ 


\begin{tabular}{|c|c|c|c|c|}
\hline Variables & $\begin{array}{l}2016 \\
(n=42)\end{array}$ & $\begin{array}{l}2017 \\
(n=69)\end{array}$ & $\begin{array}{l}2018 \\
(n=96)\end{array}$ & $P$ value \\
\hline FGM/C type, n (\%) & $3(7.1)$ & 13 (18.8) & $10(10.4)$ & \multirow[t]{5}{*}{$0.116^{b}$} \\
\hline Type I & $8(19.1)$ & $16(23.2)$ & $33(34.4)$ & \\
\hline Type II & $21(50.0)$ & $33(47.8)$ & 39 (40.6) & \\
\hline Type III & $0(0)$ & $1(1.5)$ & $2(2.1)$ & \\
\hline Type IV & $10(23.8)$ & $6(8.7)$ & $12(12.5)$ & \\
\hline \multicolumn{5}{|l|}{ Unspecified or other } \\
\hline FGM/C type, n (\%) & $3(7.1)$ & $0(0)$ & $0(0)$ & \\
\hline N90.80 & $3(7.1)$ & $0(0)$ & $0(0)$ & \\
\hline N90.81 & $8(19.1)$ & $0(0)$ & $0(0)$ & \\
\hline N90.82 & $21(50.0)$ & $0(0)$ & $0(0)$ & \\
\hline N90.83 & $7(16.7)$ & $0(0)$ & $0(0)$ & \\
\hline N90.88 & $0(0)$ & $6(8.7)$ & $12(12.5)$ & \\
\hline Z91.70 & $0(0)$ & $13(18.8)$ & $10(10.4)$ & \\
\hline Z91.71 & $0(0)$ & $16(23.2)$ & $33(34.4)$ & \\
\hline Z91.72 & $0(0)$ & $33(47.8$ & $39(40.6)$ & \\
\hline Z91.73 & $0(0)$ & $1(1.5)$ & $2(2.1)$ & \\
\hline Z91.74 & & & & \\
\hline
\end{tabular}

The FGM/C type differed significantly depending on the region of origin $(P=0.004)$ : type II and III were significantly more frequent among patients from West Africa and from East Africa, respectively [Table S2].

The calculated FGM/C prevalence was 2.29\% (95\%Cl: 1.98-2.62). We used 200 as the numerator: 207 less the seven patients with a nationality outside the 30 targeted countries.

FGM/C prevalence significantly increased over time in participating centers: $1.24 \%$ in $2016,2.32 \%$ in 2017 , and $3.32 \%$ in $2018(P<0.001)$.

FGM/C prevalence was significantly higher in women from East Africa $(P<0.001)$ [Table S3]. FGM/C prevalence in Swiss hospitals was $3.53 \%$ among inpatients from countries with the highest FGM/C prevalence ( $\geq 81 \%)$, and thus higher than among inpatients from countries with lower FGM/C prevalence $(P<0.001)$.

We calculated the FGM/C prevalence among inpatients from each at-risk country separately [Table S4] and estimated the number of inpatients who could have undergone or be at risk of undergoing FGM/C: 1648 in 2016, 1671 in 2017, and 1628 in 2018 ( $n=4947)$.

FGM/C prevalence was lower among minors (0.66\%), compared to women above 18 years old $(2.46 \%)(P<0.001)$ [Table 4]. FGM/C prevalence also varied by hospital department, with higher prevalence among inpatients in gynecology and obstetrics $(P<0.001)$. FGM/C prevalence among women and girls from at-risk countries was higher in Geneva, similar in Lausanne and Zürich, and lower in Bern $(P<$ 0.001). The estimated prevalence was higher in institutions featuring regular educational programmes about FGM/C and/or a clinic or referral physician for FGM/C. 
Table 4

Prevalence of FGM/C by category of age, hospital department, center, and educational programme attendance $(n=200$ FGM).

\begin{tabular}{|c|c|c|c|c|}
\hline Variables & Number of cases, $n$ & $\mathbf{N}$ & Prevalence, \% (95\% Cl) & $P$ value \\
\hline Category of age, n (\%) & 5 & 757 & $0.66(0.21-1.53)$ & $0.001^{a}$ \\
\hline$<18$ years & 195 & 7936 & $2.46(2.13-2.82)$ & \\
\hline \multicolumn{5}{|l|}{$>=18$ years } \\
\hline Hospital department, n (\%) & 195 & 4163 & $4.68(4.06-5.37)$ & \multirow{14}{*}{$\begin{array}{l}<0.001^{a} \\
<0.001^{b} \\
<0.001^{b}\end{array}$} \\
\hline Gynecology \& obstetrics & 2 & 1266 & $0.16(0.019-0.57)$ & \\
\hline Surgery & 1 & 2362 & $0.042(0.0011-0.24)$ & \\
\hline Medical department & 0 & 573 & $0(0-0.64)$ & \\
\hline Emergency & 2 & 374 & $0.53(0.065-1.92)$ & \\
\hline Pediatrics & 111 & 2390 & $4.64(3.84-5.57)$ & \\
\hline Center, n (\%) & 35 & 1218 & $2.87(2.01-3.97)$ & \\
\hline Geneva & 32 & 4388 & $0.73(0.50-1.03)$ & \\
\hline Lausanne & 22 & 742 & $2.96(1.87-4.45)$ & \\
\hline Bern & 54 & 5130 & $1.05(0.79-1.37)$ & \\
\hline Zürich & 146 & 3608 & $4.05(3.43-4.74)$ & \\
\hline \multicolumn{4}{|c|}{ Educational programme organised, n (\%) } & \\
\hline \multicolumn{4}{|l|}{ No or unknown (Bern, Zürich) } & \\
\hline \multicolumn{4}{|l|}{ Yes (Geneva, CHUV) } & \\
\hline
\end{tabular}

\section{Discussion}

\section{Main findings}

Our findings show that only 207 patients (2.29\%) have a coded FGM/C diagnosis, with an increase between 2016 and 2018 . There is a drastic difference between FGM/C cases coded in Swiss university hospitals $(n=207)$ and the possible number of women and girls with FGM/C in these hospitals based on our indirect estimates $(n=5047)$. Our results suggest that FGM/C is not accurately diagnosed, recorded and/or coded in Swiss university hospitals. Moreover, most women and girls came from Eritrea and Somalia, where FGM/C prevalence exceeds $80 \%$, and where type III is frequent, the latter type being easier to identify, and associated with more long-term complications ${ }^{1}$. Infibulation was indeed the most frequent type among inpatients from East Africa.

Seven inpatients with an FGM/C code did not have the nationality of a country where the practice is usually performed. The nationality recorded or FGM/C coding might be incorrect. Alternatively, these women come from FGM/C practicing countries but possess another nationality, and underwent FGM/C before migrating, or afterwards while visiting their country of origin. In such case, and if coding is accurate, monitoring FGM/C prevalence with ICD codes might give more reliable results than indirect estimates and overcome the issue of nationality and ethnicity.

Coding was significantly higher in gynecology and obstetrics compared to other departments. Obstetricians and gynecologists routinely examine the external genitalia and might be more trained to recognize FGM/C. Furthermore, our results suggest that pregnancy and 
delivery are critical times for diagnosing FGM/C, because it was significantly more coded in obstetrics than in gynecology. Only two girls in pediatrics and two women in urology were coded with FGM/C.

The prevalence of $\mathrm{FGM} / \mathrm{C}$ codes in minors $(0.66 \%)$ was significantly lower than in adult women $(2.46 \%)$. Belonging to a new generation of immigrants, length of stay, and migration in a country where FGM/C is illegal could explain why it is less frequent among minors $6,7,11$. However, insufficient screening and routine genital examinations among pediatricians, or absent documentation can also explain the low numbers $^{22}$. A specific code for "risk of FGM/C" might facilitate screening and prevention ${ }^{16}$.

Longstanding training and protocols about FGM/C in Geneva and Lausanne could explain why FGM/C prevalence in these hospitals was higher than in Bern, even though Bern numbered more patients from FGM/C practicing countries. At HUG for instance, a retrospective review of the medical files of patients who attended the FGM/C outpatient clinic between 2010 and 2012 revealed missed and misdiagnosis of FGM/C in more than one-third of cases ${ }^{17}$. Therefore, the obstetric and gynecologic divisions implemented several interventions: update of protocols for the care of women and girls with FGM/C, learning tools with drawings, pictures and videos ${ }^{26}$, workshops for midwives, and simulation programmes on defibulation. Since 2010, workshops were also organized in pediatrics, travel medicine, HIV clinic, infectious disease, and primary care. In 2017, the HUG hosted an International expert symposium on the care of women and girls with FGM/C and on prevention ${ }^{27}$. In 2012, the HUG's division of gynecology introduced an FGM/C checkbox in electronic medical forms to record FGM/C and its type. An update in February 2018 [Figures 1 \&2] added the description of FGM/C types and subtypes in gynecology and obstetrics. This may have facilitated screening and recording, explaining why FGM/C codes almost tripled between 2017 and 2018.

According to a survey run by the Swiss Network against Female Circumcision in 2017 (unpublished, data obtained from the authors), FGM/C was taught at the medical faculties of the Universities of Geneva, Lausanne and Fribourg but not in Bern, whose university hospital admitted 4388 women and girls from FGM/C practicing countries between 2016 and 2018. This might partially explain the higher FGM/C prevalence in Geneva and Lausanne. Zürich's medical faculty did not reply to this survey.

\section{Strengths and Limitations}

One strength of the study was the use of ICD-10 codes for estimating FGM/C prevalence, making it easily reproducible to allow comparison of data over time, and after specific interventions ${ }^{16}$.

The main weakness is that we could only collect data of patients, for whom FGM/C had been coded, and undercoding is evident. FGM/C is probably not recorded/coded when the reason for hospitalization and FGM/C are not related. However, even when they are related, FGM/C recording/coding is probably missing: the calculated prevalence of $\mathrm{FGM} / \mathrm{C}$ among 4163 inpatient women in obstetrics and gynecology is only $4.68 \%$.

We limited our study to university hospitals. Basel's University Hospital could not provide the data requested, but we hypothesize that we would have found equally low FGM/C prevalence. We did not study regions without university hospitals, such as Tessin, on the Italian border, where hospitals could admit migrant women and girls with or at risk of $\mathrm{FGM} / \mathrm{C}^{8}$.

We included hospitalized patients only. It would be interesting to analyze data of outpatient women and girls in pediatrics, travel medicine, infectious disease, primary care services, and migrants' physical and mental health programmes.

\section{Interpretation}

The number of inpatients with an FGM/C diagnosis out of all women and girls potentially living with FGM/C is low in all hospitals and specialties, including gynecology and obstetrics. We believe that FGM/C coding indirectly reflects awareness of the phenomenon. Thus, if $\mathrm{FGM} / \mathrm{C}$ is not recognized nor discussed, women and girls living with $\mathrm{FGM} / \mathrm{C}$ cannot access specific care, health and legal information and prevention.

Our study suggests that training healthcare professionals and medical students increases the number of patients coded with FGM/C. A study conducted in Belgium showed that more patients were coded with FGM/C after delivering information on FGM/C and its management ${ }^{28}$. The introduction of an FGM/C checkbox in electronic medical charts also seems to facilitate the diagnosis. Similar use of electronic tools facilitated identification of intimate partner violence, together with routine protocols on appropriate screening and counseling ${ }^{29}$. Since November 2019, at HUG, the FGM/C checkbox is linked to a standardized form where physicians, nurses and midwives can record the type, subtype and complications identified, and access an illustrated description from a learning tool for each item $^{26}$. 


\section{Conclusion}

The present study shows that assessing FGM/C coding through ICD-10 is feasible but FGM/C coding capacities among inpatients in Swiss university hospitals are low.

Future policies should include training on appropriate screening, diagnosis, management and referral in case of FGM/C. Training should be organized in different specialties such as urology, obstetrics and gynecology, infectious diseases, general practice, pediatrics and psychiatry ${ }^{30}$, and stress the importance of recording and coding. Certified interpreters and coders should also receive training. Finally, professionals in obstetrics, pediatrics, primary care, and travel medicine should be able to identify children at risk and discuss prevention, national laws on FGM/C and child's rights ${ }^{21-24,31}$. Sensitizing and teaching about FGM/C in existing pre-graduate classes, such as anatomy, gynecology and obstetrics, urology, infectious disease, pediatrics, psychiatry and primary care could improve standard training.

Our next step is to assess knowledge, attitudes and practice of healthcare professionals in the same hospitals to tailor training programmes and tools that can improve screening, prevention, diagnosis and management of FGM/C. We will also analyze our data according to the belonging of the included institutions to Swiss Hospitals for equity, a network aiming at improving healthcare access for underprivileged groups, regardless of their origin, language and socioeconomic situation. Routine availability of certified interpreters, like in Geneva and Lausanne, might facilitate diagnosis, recording and coding of FGM/C.

\section{Declarations}

\section{Details of ethics approval}

Ethics approval was granted by the state of Geneva SwissEthics committee, for protocol number 2018-01851 on the 19th of December, 2018 in accordance with the Declaration of Helsinki. An exemption of informed consent was granted for the use of anonymized data extracted from the university hospitals databases.

\section{Consent for publication}

All authors have approved the manuscript for submission.

\section{Availability of data and materials}

The datasets used and/or analysed during the current study available from the corresponding author on reasonable request.

\section{Competing interests}

No competing interests to declare

\section{Funding}

Swiss Network Against Female Genital Mutilation, Caritas Switzerland, The Federal Office of Public Health [4] which funded the study.

\section{Authors' contributions}

JA designed and directed the project. SCC collected the data, together with JA and MH. SCC and AGA did the data analysis. MH and JA wrote the manuscript in collaboration with SCC and AGA. All the authors reviewed and approved the manuscript.

\section{Acknowledgments}

Monique Lamuela Naulin (Department of the Woman, the Child and the Adolescent) who provided figures and information on HUG medical records.

Marisa Birri (Swiss Network Against Female Genital Mutilation) who provided information on pre-grade curricula and FGM/C.

\section{References}

1. World Health Organization. Care of women and girls living with female genital mutilation: a clinical handbook. 2018. [cited 2019 Jan 18]. Available from: https://www.who.int/reproductivehealth/publications/health-care-girls-women-living-with-FGM/en/. 
2. World Health Organization. Types of female genital mutilation. 2020. [cited 2020 Apr 18]. Available from:https://www.who.int/sexual-and-reproductive-health/types-of-female-genital-mutilation.

3. UNICEF. Female Genital Mutilation/Cutting: a global concern. 2016. [cited 2019 Jan 18]. Available from: http://www.unicef.org/media/files/FGMC_2016_brochure_final_UNICEF_SPREAD.pdf.

4. Van Baelen L, Ortensi L, Leye E. Estimates of first-generation women and girls with female genital mutilation in the European Union, Norway and Switzerland. The European Journal of Contraception \& Reproductive Health Care. 2016;21(6):474-82.

5. Federal Office of Public Health. Motion report on FGM. 2015. [cited 2019 Nov 6]. https://www.bag.admin.ch/bag/en/home/strategieund-politik/nationale-gesundheitsstrategien/gesundheitliche-chancengleichheit/chancengleichheit-in-dergesundheitsversorgung/massnahmen-gegen-weibliche-genitalverstuemmelung.html.

6. European Institute for Gender Equality. Female genital mutilation. Estimating the number of girls at risk in the European Union: Belgium, Greece, France, Italy, Cyprus and Malta - Report. 2018. [cited 2019 Aug 7]. Available from: https://eige.europa.eu/publications/estimation-girls-risk-female-genital-mutilation-european-union-report-0.

7. European Institute for Gender Equality. Female genital mutilation. Estimating the number of girls at risk in the European Union: Report. 2015. [cited 2019 Aug 7]. Available from: https://eige.europa.eu/publications/estimation-girls-risk-female-genital-mutilationeuropean-union-report.

8. Ortensi LE, Farina P, Leye E. Female genital mutilation/cutting in Italy: an enhanced estimation for first generation migrant women based on 2016 survey data. BMC Public Health. 2018;18(1):129.

9. Equality Now, City University London. London Institute for Women's health, and FORWARD. Research methodological workshop report: estimating the prevalence of FGM in England and Wales. 2012. [cited 2020 Mar 20]. Available from:

https://www.equalitynow.org/research_methodological_workshop_report_estimating_the_prevalence_of_fgm_in_england_and_wales.

10. Ortensi LE, Farina P, Menonna A. Improving estimates of the prevalence of Female Genital Mutilation/Cutting among migrants in Western countries. Demographic Research. 2015;32:543-62.

11. Vogt S, Efferson C, Fehr E. The risk of female genital cutting in Europe: Comparing immigrant attitudes toward uncut girls with attitudes in a practicing country. SSM - Population Health. 2017;3:283-93.

12. Cappa C, Van Baelen L, Leye E. The practice of female genital mutilation across the world: Data availability and approaches to measurement. Glob Public Health. 2019;14(8):1139-52.

13. Elmusharaf S, Elhadi N, Almroth L. Reliability of self reported form of female genital mutilation and WHO classification: cross sectional study. BMJ. 2006;333(7559):124.

14. Johansen REB, Ziyada MM, Shell-Duncan B, Kaplan AM, Leye E. Health sector involvement in the management of female genital mutilation/cutting in 30 countries. BMC Health Services Research. 2018;18(1):240.

15. Chou D, Cottler S, Khosla R, Reed GM, Say L. Sexual health in the International Classification of Diseases (ICD): implications for measurement and beyond. Reprod Health Matters. 2015;23(46):185-92.

16. Cottler-Casanova S, Horowicz M, Gieszl S, Johnson-Agbakwu C, Abdulcadir J. Coding Female Genital Mutilation/Cutting and its complications using the International Classification of Diseases: a commentary. BJOG. 2020.

17. Abdulcadir J, Dugerdil A, Boulvain M, Yaron M, Margairaz C, Irion O, et al. Missed opportunities for diagnosis of female genital mutilation. International Journal of Gynecology \& Obstetrics. 2014;125(3):256-60.

18. Ali AA. Knowledge and attitudes of female genital mutilation among midwives in Eastern Sudan. Reprod Health. 2012;9:23.

19. Cappon S, L'Ecluse C, Clays E, Tency I, Leye E. Female genital mutilation: Knowledge, attitude and practices of Flemish midwives. Midwifery. 2015;31(3):e29-e35.

20. Turkmani S, Homer C, Varol N, Dawson A. A survey of Australian midwives' knowledge, experience, and training needs in relation to female genital mutilation. Women Birth. 2018;31(1):25-30.

21. Tantet C, Aupiais C, Bourdon M, Sorge F, Pages A, Levy D, et al. Female genital mutilation: an evaluation of the knowledge of French general and specialized travel medicine practitioners. J Travel Med. 2018;25(1).

22. González-Timoneda A, Ruiz Ros V, González-Timoneda M, Cano Sánchez A. Knowledge, attitudes and practices of primary healthcare professionals to female genital mutilation in Valencia, Spain: are we ready for this challenge? BMC health services research. 2018;18(1):579-

23. Young J, Rodrigues KK, Imam B, Johnson-Agbakwu C. Female Genital Mutilation/Cutting-Pediatric Physician Knowledge, Training, and General Practice Approach. J Immigr Minor Health. 2019.

Page 12/14 
24. Sureshkumar P, Zurynski Y, Moloney S, Raman S, Varol N, Elliott EJ. Female genital mutilation: Survey of paediatricians' knowledge, attitudes and practice. Child Abuse \& Neglect. 2016;55:1-9.

25. World Health Organization. ICD-10 Training Tool. Structure of the classification and how to code. 2010. [cited 2019 Aug 7]. Available from: http://apps.who.int/classifications/apps/icd/icd10training/ICD-10\%20training/Start/index.html.

26. Abdulcadir J, Catania L, Hindin MJ, Say L, Petignat P, Abdulcadir O. Female Genital Mutilation: A Visual Reference and Learning Tool for Health Care Professionals. Obstet Gynecol. 2016;128(5):958-63.

27. Abdulcadir J, Alexander S, Dubuc E, Pallitto C, Petignat P, Say L. Female genital mutilation/cutting: sharing data and experiences to accelerate eradication and improve care. Reprod Health. 2017;14(Suppl 1):96-.

28. European Institute for Gender Equality. A pilot study for identifying adequate hospital procedures in FGM cases. 2016 . [cited 2019 Aug 8]. Available from: https://eige.europa.eu/gender-based-violence/good-practices/belgium/registration-fgm-hospitals.

29. Alvarez C, Fedock G, Grace KT, Campbell J. Provider Screening and Counseling for Intimate Partner Violence: A Systematic Review of Practices and Influencing Factors. Trauma Violence Abuse. 2017;18(5):479-95.

30. 30. Berg RC, Underland V, Odgaard-Jensen J, Fretheim A, Vist GE. Effects of female genital cutting on physical health outcomes: a systematic review and meta-analysis. BMJ Open. 2014;4(11):e006316.

31. Chiodini J. Female Genital Mutilation, "vacation cutting" and the travel medicine consultation. Travel Med Infect Dis. 2017;18:87-91.

\section{Figures}

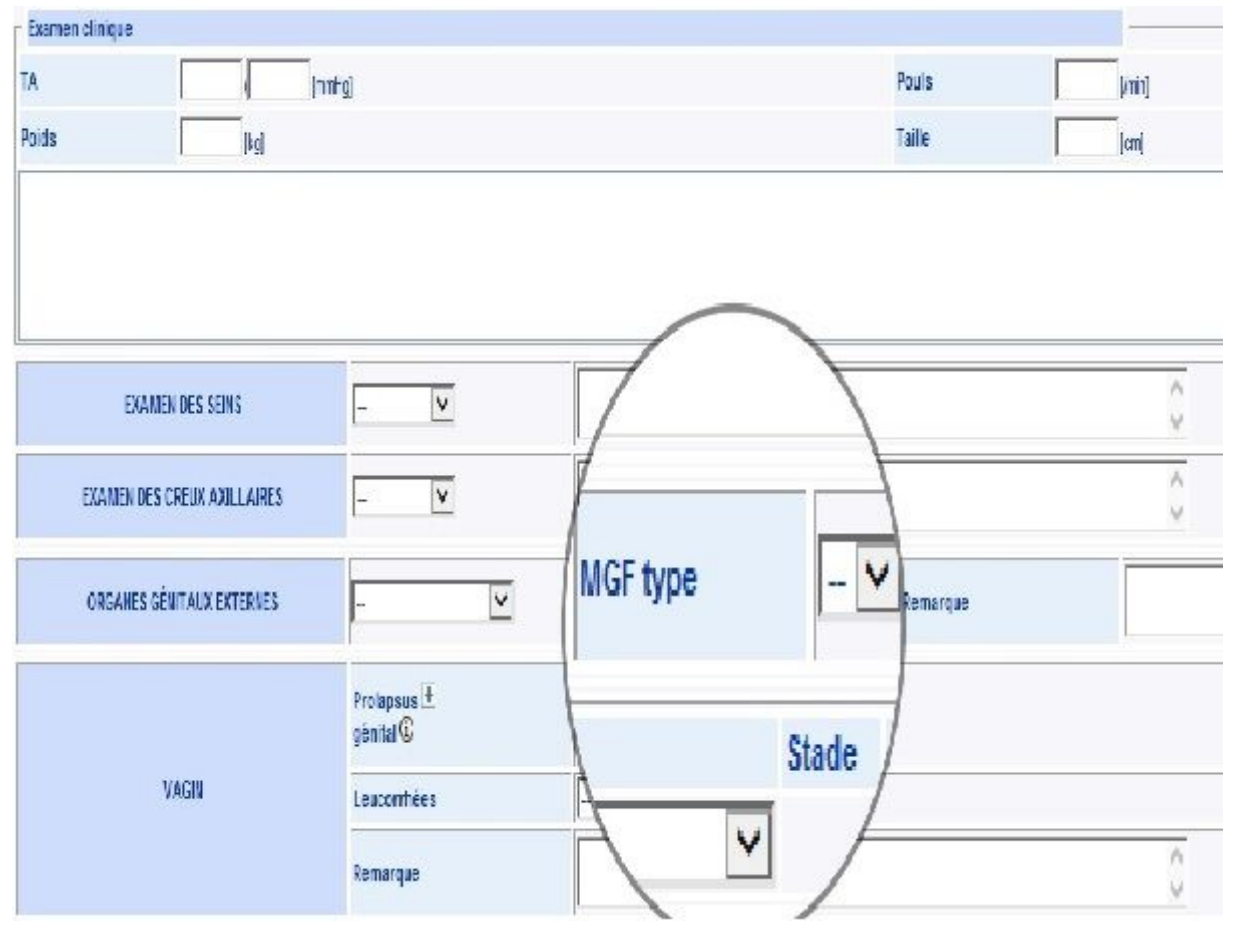

\section{Figure 1}

FGM/C checkbox in the gynaecological electronic medical chart 
^ MGF - Mutilations Génitales Féminines

V Type I: Ablation partielle ou totale du clitoris et/ou du prépuce (clitoridectomie)

Photos classification Type|

Type la, ablation du capuchon clitoridien ou du prépuce uniquement

OType lb, ablation du clitoris et du prépuce

T Type II : Ablation partielle ou totale du clitoris et des petites lèvres, avec ou sans excision des grandes lèvres (excision)

Photos classification Type II

OType lla, ablation des petites lèvres uniquement

OType llb, ablation partielle ou totale du clitoris et des petites lèvres

- Type llc, ablation partielle ou totale du clitoris, des petites lèvres et des grandes lèvres $X$

V Type III : Rétrécissement de l'orifice vaginal avec recouvrement par Iablation et l'accolement des petites lèvres et/ou des grandes lèvres, avec ou sans excision du clitoris (infibulation) Photos classification Type III

OType Illa, ablation et accolement des petites lèvres

OType Illb, ablation et accolement des grandes lèvres

désinfibulée $\bigcirc$ non désinfibulée

v Type IV : Non classées : toutes les autres interventions nocives pratiquées sur les organes génitaux féminins à des fins non thérapeutiques, telles que la ponction, le percement, lincisi Photos classification Type IV

OType IV : Non classées : ponction

OType IV : Non classées : percement

OType IV : Non classées : incision

OType IV : Non classées : scarification

OType IV : Non classées : cautérisation

- OType IV : Non classées : autres interventions nocives

\section{Figure 2}

FGM/C Type and Description in gynaecological electronic medical chart

\section{Supplementary Files}

This is a list of supplementary files associated with this preprint. Click to download.

- FGMCcodingSwitzerlandappendixBMC.docx

- SITables.pdf 